\title{
Ecological risks during offshore construction of oil platforms
}

\author{
Ksenia Derevtsova ${ }^{1,},{ }^{*}$ Vladislav Ginevskii ${ }^{1}$, Gleb Kataev ${ }^{1}$, Semion $\mathrm{Kim}^{1}$, and Polina \\ Veselova $^{1}$ \\ ${ }^{1}$ Far Eastern Federal University, Russkiy Island, Russia
}

\begin{abstract}
The article tells about the risks of low-culture construction of oil facilities on the Arctic shelf. The long-term, practically neglected exploitation of the unique natural resources of the Russian North and the low culture of their development led in a number of its regions, including the waters of the Arctic seas with islands, to an emergency ecological situation - the partial and sometimes complete destruction of the fragile Arctic natural habitat of the small peoples of the North and the created cities and villages. Without proper environmental support, economic activities continue in the field of extraction, transportation and processing of natural resources. The progressive pollution of rivers and lakes leads to a qualitative depletion of water resources - a change in the composition of the waters of the Arctic Ocean. The danger of oil pollution of the marine environment is associated with plans for its production on the continental shelf of the Russian Federation. The oil and gas production complex in the Russian Arctic regions are being formed on the basis of already discovered fields and will develop as other promising fields are developed.
\end{abstract}

\section{Introduction}

The Arctic, in comparison with other regions of the planet and densely populated regions of the Russian Federation, remains relatively clean. However, in places of intensive economic and economic activity in the Russian Arctic, environmental "hot spots" ("impact zones") have arisen, which risk turning into emergency zones, since the scale of environmental degradation there has reached dangerous levels. It should be borne in mind that the disturbance of fragile Arctic ecosystems can be irreversible.

Impact zones are areas of seas and oceans that are prone to pollution as a result of anthropogenic impact. An impact region is understood as a territorial complex of ecosystems of different spatial and temporal scales located near a point source of emission of pollutants (technogenic environmental pollutants) and exposed to a local toxic load from this source. The impact region is a specific spatial structure of concentrically located zones with varying degrees of pollution and, accordingly, different levels of ecosystem transformation. Usually, three or four transformation zones are distinguished: technogenic desert, impact, buffer and background (the latter, strictly speaking, is not included in the

\footnotetext{
*Corresponding author: blazblue@list.ru
} 
impact region). The spatial boundary of the impact region passes where, using modern methods, it is no longer possible to separate the local effect of the toxic load from naturally caused changes, as well as background (regional and global) fallout of pollutants. This boundary separates the impact region from the background territory. In the Arctic zone of Russia, 27 regions were identified (11 - on land, 16 - in the seas and the coastal zone), which received the name "impact", where these processes have already led to the strongest transformation of the natural geochemical background, atmospheric pollution, degradation of vegetation cover, soil and soils, the introduction of harmful substances in the food chain, increased morbidity of the population (Table 25). The distribution of impact areas is extremely uneven. The four main hotbeds of tension are the Murmansk region $(10 \%$ of the total emission of pollutants), the Norilsk agglomeration (more than $30 \%$ ), the regions for the development of oil and gas fields in Western Siberia (more than 30\%) and the Arkhangelsk region (a high degree of pollution with specific substances).

The extremely high ecological vulnerability of the Arctic is due to the intensive (especially over the last 40-60 years) development of its resources with the creation of large mining, mining and metallurgical, oil and gas production complexes. To this is added the long-term functioning of the nuclear test site on Novaya Zemlya, underground nuclear explosions for industrial purposes, the disposal of liquid and solid radioactive waste, as well as the peculiarity of the migration of chemical elements in the circumpolar region of our planet.

In the Central Arctic alone, the Norilsk Combine emits millions of tons of sulfur dioxide and thousands of tons of harmful dust into the atmosphere. The area of affected and dried up forests here exceeds 50 thousand hectares, and the length of the "ammonia footprint" reaches along the river valley Rybnoy and further south $350 \mathrm{~km}$.

Chemical pollution in the Arctic is dangerous due to the low assimilation capacity of its marine and land ecosystems. The concentration of heavy metals is growing almost everywhere in soils, plants and animals, in water and snow, sea ice, bottom sediments. More than $30 \%$ of polluted wastewater enters the aquatic environment of the region. Many parts of the water area of the Barents, White, Kara Seas and the Laptev Sea have a concentration of pollutants that is $2-3$ times higher than the MPC. Among the impact areas with the highest levels of pollution are the Kola Bay of the Barents Sea, the Pechora Sea and the lower reaches of the river Pechora, Ob Bay.

The pollution level of the Arctic seas is lower in comparison with other seas. However, the accumulation of certain pollutants in specific places and populations of living organisms causes them to enter the food of local residents, and their concentration is often higher than in food outside the Arctic.

The Arctic is distinguished by a high vulnerability of the natural environment to anthropogenic impact and a slow rate of restoration of disturbed natural objects (natural ecosystems, landscapes). Moreover, this macroregion is more susceptible to climate change than others.

At present, the AZRF, especially the regions and nodes of intensive technogenic development and the formation of full-fledged territorial-production complexes, are under powerful anthropogenic and technogenic impact.

\section{Risks description}

The main environmental problems of the Arctic zone of the Russian Federation are:

pollution of the marine environment in areas of development, especially in coastal zones (oil pollution of the marine environment, transboundary transport of radionuclides by sea currents, abandoned sunken ships); unsatisfactory condition of atmospheric air in 
settlements located near industrial enterprises of cities and towns; the critical state of water bodies, treatment facilities and sources of drinking water supply (for $70 \%$ of administrative territories, the issues of ensuring sanitary and hygienic standards for drinking water supply are acute); degradation of soil and vegetation as a result of the accumulation of production and consumption waste, oil and chemical pollution (including persistent organic pollutants); radiation pollution of the environment (storage sites for spent nuclear fuel, used radioisotope thermoelectric generators); threats to the biological diversity of flora and fauna (about 20 species of birds and mammals inhabiting the Arctic are listed in the Red Book of the Russian Federation); lack of an effective system for monitoring the state of hazardous sources of pollution and a quick response in the event of emergency natural and man-made situations.

A significant contribution to the pollution of the Arctic is made by emissions and discharges of industrial waste, accidental spills of oil and oil products on land and in the sea, the formation of natural gushing oil sources in the oil and gas regions of the Arctic coast, errors in the operation of engineering structures in the coastal zone of the Arctic seas, discharges of household waste from the sea. and river vessels, emissions of combustion products or residues of oil, gas, gasoline, diesel fuel, aviation kerosene into the atmosphere during operation, maintenance and repair work of all types of transport (water, air, land), other unpredictable pollution of the Arctic environment as a result of accidents and negligence of various scales. Figure 1 shows us an example of coastal oil pollution due of irresponsible usage of oil platforms.

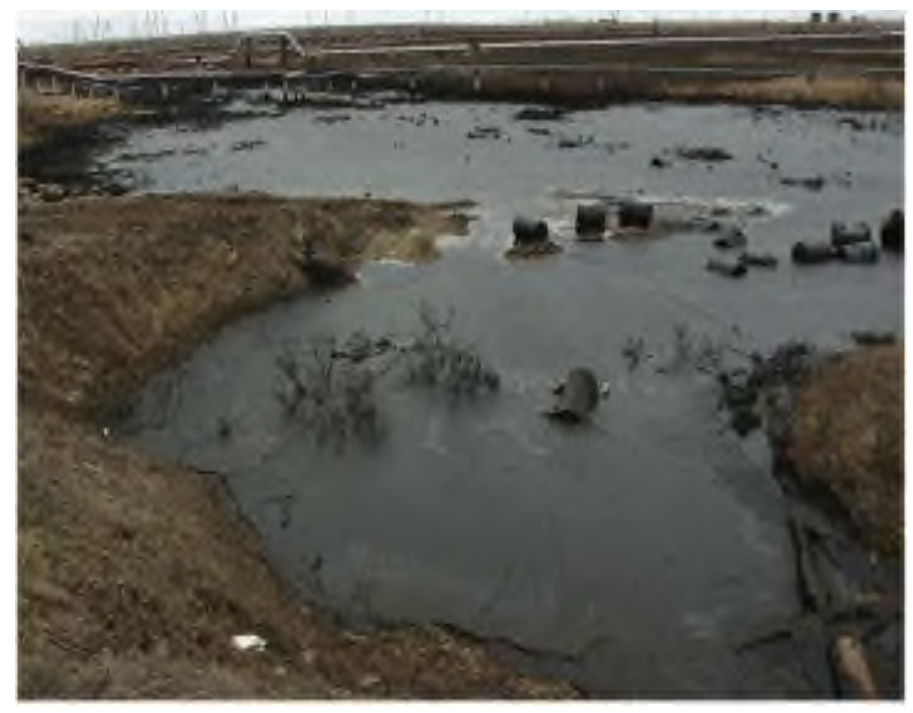

Fig. 1. Coastal oil pollution.

On the basis of the development of the shelf deposits of the Prirazlomnoye, Dolgan, Varandey Sea, Medyn Sea, it is planned to create the first offshore oil and gas production center, which causes serious environmental concerns. And all this in the absence of a reliable, proven methodology for responding to an accidental oil spill in ice. To transport oil from all the fields being developed, it will be necessary to build infield and interfield oil pipelines. And these pipelines can leak if the technology of their construction is violated. Even a small leak can cause terrible water and soil pollution.

The impact of the oil and gas complex on natural systems can be traced in a number of areas: direct extraction of resources (oil, gas, gas condensate, surface and artesian waters, nonmetallic building materials, timber, etc.); use of resources (water resources, land 
resources, flora and fauna resources, fish resources); entry of pollution into the environment (emissions into the atmosphere, discharges into water bodies and onto the relief, injection of wastewater into underground horizons, waste, noise and vibration, electromagnetic radiation, thermal and light pollution, etc.); change of relief and landscape. Large sources of air pollution are oil and gas companies that flare associated gas. During the development of oil fields, about 10 billion $\mathrm{m} 3$ of associated petroleum gas (APG) is produced, while the annual volume of flared gas is about 5 billion $\mathrm{m} 3$. Figure 2 shows a gas torch releasing thousands of cubic meters of carbon into the atmosphere.

One of the main problems today is the growth of pollution of surface waters with oil products. In many rivers of the Autonomous Okrug, the average concentration of oil products exceeds the MPC by 10-20 times, but sometimes by 3-60 times. The most difficult situation is observed along the Ob, Poluy, Nadym, Pravaya Khetta, Pur rivers. Oil products enter water bodies with wastewater from oil refining, oil production, chemical and other industries, as well as during the transportation of oil by water. One of the world's largest pipeline systems for the transportation of natural gas operates in the Yamalo-Nenets Autonomous Okrug. Pipeline transport is represented by the Unified Gas Transportation System (OJSC Gazprom), as well as by the Unified Oil Transportation System of AK Transneft. Trunk and infield (technological) pipelines are a source of significant hydrocarbon pollution. Due to the high density of the river network within the Okrug, oil pipelines often cross water bodies. If a pipeline breaks down at a river or lake passage, from several hundred to several thousand cubic meters of oil products can be thrown into the water. In case of accidents, the concentration of oil and oil products in the water can reach 200-300 mg / 1 . Accidents on field oil pipelines occur much more often (5-6 times) than on main ones. This is due to the longer length of field oil pipelines (compared to main pipelines), and also because their pipes are very susceptible to internal corrosion due to the effect of aggressive water-gas-oil emulsion.

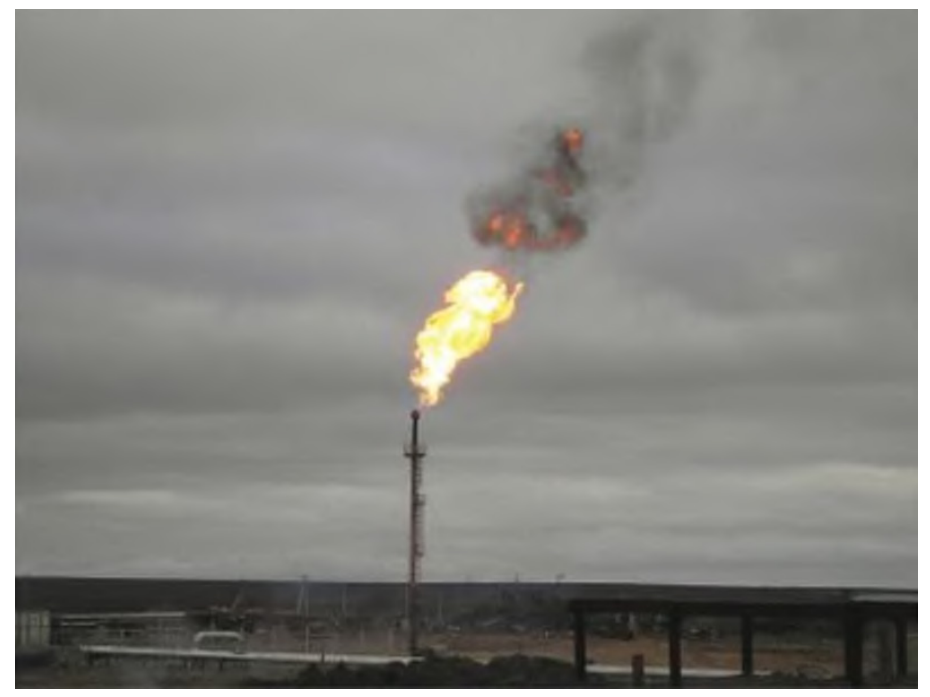

Fig. 2. Working gas torch.

Also, one of the long-term problems of offshore oil production is the fact that very often the negotiation bases are preserved not for environmental safety requirements. A lot of metal and plastic remains, including barrels of oil and fuels and lubricants. Currently, most of the barrels and containers have fallen into disrepair. Dozens of tons of fuels and lubricants (gasoline, oil, diesel fuel) remained in them. From rusted barrels, these 
substances are discharged onto the ground, which leads to contamination of the territory. An example is the Wrangel Island. In 2004, Wrangel Island was given the status of a World Natural Heritage Site with one condition - cleaning the area from scrap metal and technical waste. Figure 3 depicts oil barrels left after the conservation of the onshore base serving the construction of an offshore production platform.

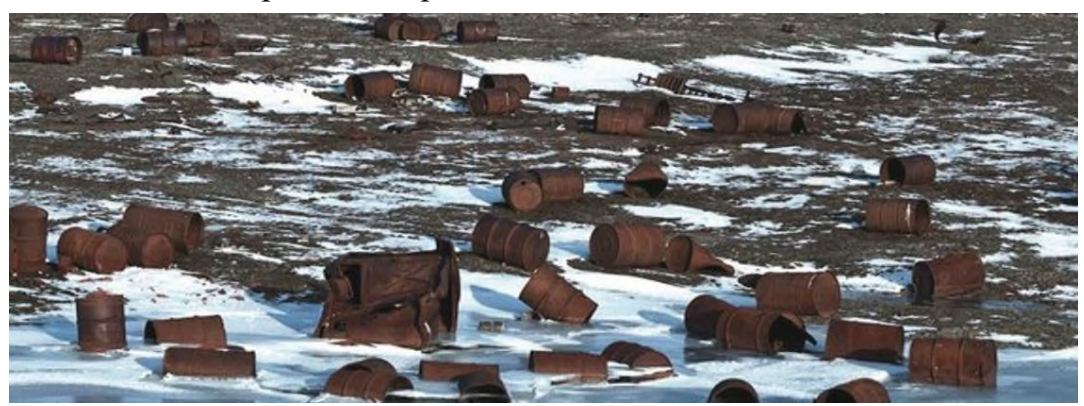

Fig. 3. Conservation waste.

Accidents in the production of petroleum hydrocarbons are associated with imperfect production technology, poor quality or unacceptable wear and tear of equipment, construction defects, violations of the technology of certain types of work, metal corrosion (determined by the specifics of natural landscapes where production is carried out), mechanical causes (including natural disasters, in particular earthquakes), and other factors. Depressurization of wells, destruction of infield and interfield pipelines, emissions and leaks at desalting and degassing points, tanks for storing oil and oil products, etc. Total losses of petroleum hydrocarbons during oil production and transportation are estimated from 3 to $8-10 \%$ of annual production ... As a result, a significant amount of technogenic petroleum hydrocarbons has already accumulated in the soils and grounds in the oilproducing regions during the operation of the fields and the operation of pipeline systems, and their content is constantly increasing.

An extremely serious problem in the fields is the condition of soil-ground and groundwater itself (including drinking). When only $1 \mathrm{~m} 3$ of oil is filtered from the surface of the earth, the potentially possible area of contamination of the surface layer of groundwater is more than 5 thousand $\mathrm{m}$. As a result of oil production over the past 30-35 years, the natural environment of the Arctic zone has been subjected to an unprecedented oil pressure (especially if oil producing enterprises of accidents with environmental consequences). All landscape components undergo a profound transformation, soilgeochemical and landscape processes change, which in turn creates a more "aggressive" natural environment with respect to technical objects. Secondary processes - the consequences increase the potential accident rate in the field.

The offshore construction trend is not quite where nature wants it to be. This is how the safety requirements for the extraction, transportation and processing of hydrocarbon raw materials are not met, as a result, an increase in the number of accidents is observed. The high level of accidents at the facilities of the oil and gas industry is also due to a significant degree of wear and tear of the main equipment, pipelines and structures, low rates of implementation of modern technologies, insufficient equipment with reliable automation and telemechanics systems. An increase in the number of accidents, oil leaks, and chemical emissions into the atmosphere contributes to environmental pollution and, as a result, to a change in its state. The average size of accidental spills is estimated at 0.5-1.5 (2.0) hectares, while the area of catastrophic spills is square $\mathrm{km}$ (for example, the area of the Vosey - Headworks accident exceeded $60 \mathrm{~km} 2$ ). The discharge into the environment of such huge volumes of petroleum hydrocarbons and the pollution of soils, surface, ground 
and ground waters leads not only to ecological problems on very large land areas, large economic losses, but due to the high mobility of pollutants pose a serious threat to aquatic ecosystems, including the seas of the Arctic Basin. The main pollutants on the territory of the fields are oil, oil products, condensates, oil in case of accidental emissions and losses during transportation; waste water of various salinity; hydrocarbons, phenols, surfactants and additives to them; corrosion inhibitors, hydrogen sulfide, iron, mechanical impurities, salts (especially a lot of chloride), rare and trace elements; polymers (polyacrylomides, polysaccharides); alkalis, thermal effects, products of incomplete combustion of associated gases and condensate (PAH emissions, including 3,4-benzpyrene), etc.

When developing oil and gas bearing areas on the shelf, there is an urgent need to predict the spread of spilled oil products and develop adequate means and methods for eliminating the consequences of pollution of the sea area and coastline in Arctic natural conditions.

The behaviour of oil in cold Arctic seas, especially in ice conditions, is significantly different from the behaviour of oil in the event of an oil spill in other regions of the Earth.

The behaviour of oil in open water obeys well-known equations and lends itself well to mathematical modelling. At the same time, the behavior of oil under the ice, in the openings of ice, on its surface is currently practically unpredictable and very difficult to model. Oil under the ice, without sticking to it, accumulates in its underwater irregularities, while mixing under the action of the current. Oil can remain under ice and snow for a long time (up to several months) without significant changes. The various oil spill scenarios proposed for arctic conditions show that any spill always ends up onshore in any spill. In the Arctic, this means that oil, if it hits the shore, is almost impossible to remove, so it is extremely important that the OSR preparedness strategy is based primarily on ensuring the collection, destruction of oil by burning and dispersing in the open sea.

The existing system of preparedness to respond to all kinds of oil spills in the sea is not able to ensure environmental safety with the planned volumes of oil and oil products transportation in the Arctic.

Among the whole set of environmental problems arising in the preparation and development of oil and gas bearing regions of the northern shelf, the problem of oil spills is undoubtedly one of the most acute. When developing the Prirazlomnoye fields, the probability of 1 to 6 accidental spills of oil products per year ranges from 60 to $99.8 \%$ with a possible spill volume of up to $10,000 \mathrm{~m} 3$. The spreading area of oil can be $300-350 \mathrm{~km} 2$.

Scientists have calculated the evolution and drift of the oil slick for the southeastern part of the Barents Sea during the ice-free period based on real hydrometeorological data for 6 years (May 1988 - May 1994). The contamination probability calculation was carried out for a large spill of 10,000 m3 of oil, which may be associated with a collapse of an oil pipeline or a tanker disaster. The hypothetical spill was generated every day during the entire calculation period at the point of the Prirazlomnoye field and was tracked until the slick completely disintegrated. The trajectories of the spot center movement were plotted on a map every hour. The trajectory fields were used to calculate the probabilities of the oil slick carrying out to different areas of the sea. It was found that such a spill at the Prirazlomnoye field could lead to pollution of any area of the southeastern part of the Barents Sea. The maximum slick area will be $300-350 \mathrm{~km} 2$. The probability of an oil release on the coastal areas closest to the site of the hypothetical spill - Gulyaevskie Koshki, Vaigach, Dolgiy islands - is 5-7\%. The minimum time interval from the moment of the spill to the moment of being washed ashore will be about 1 day. 


\section{Oil elimination}

Elimination of the consequences of accidental oil spills is carried out by mechanical, physicochemical and biological methods. It is considered preferable to use primarily mechanical and physical means, the use of which seems to be the most accessible, and the result is immediately visible. However, traditional methods do not provide complete cleaning, especially in remote areas of the Arctic, where their application is difficult. In these conditions, the development of alternative environmentally friendly technologies for liquidating the consequences of oil spills becomes urgent. These technologies are based on the principle of biostimulation of natural self-purification processes through the use of biosorbents and biogenic additives. In the course of such experiments, it was found that biosorbents, due to the development of colonies on the surface of the carrier material, are able to maintain high microbiological activity at low temperatures and even under ice.

Typically, oil spill response systems rely on a combination of mechanical recovery techniques and two main non-mechanical technologies for cleaning or treating spilled oil: in-situ incineration and dispersants. However, any of these responses may be severely limited or even impossible due to the harsh environmental conditions that characterize operations in the Arctic.

Most of these technologies require the use of airborne and naval facilities and trained personnel for their proper deployment and operation. The remote location and lack of infrastructure can greatly complicate the operation of these response systems. The cumulative impact of these constraints can make oil spill response nearly impossible for extended periods of time in arctic and sub-arctic areas.

In almost all Arctic regions there are seasons during which natural and climatic conditions impede the safe or effective implementation of adequate oil spill response measures. These response delays exist during periods when the available technologies cannot be effective or, as a result of the prevailing conditions, their application is impossible due to operational or safety constraints.

The increase in exploration and production in the Arctic increases the likelihood of oil spills from offshore oil platforms, oil spills from associated pipelines, storage tanks, and oil offloading operations. At the same time, as a result of changes in sea ice conditions, new navigation routes are opening up in the Arctic. The likelihood of oil spills increases with the number of ships and the volume of oil and oil products that are both transported and used by ships as fuel. For the shipping routes already existing in the Arctic today, this means denser ship traffic over a longer navigation period; and new sea lanes will create shipping risks and associated oil spill risks for more and more Arctic ecosystems.

Offshore oil spills can occur at any stage of oil production, storage or transportation. Potential sources of oil spills include well blowouts during subsea exploration or production, blowouts or leaks from subsea pipelines, leaks from onshore storage tanks or onshore pipelines, and ship accidents. transporting oil, or fuel spills from ships. Arctic conditions such as moving ice, low temperatures, limited visibility or total darkness, high speed winds and extreme storms increase the likelihood of accidents or errors that could lead to an oil spill.

There are several characteristics of arctic environmental conditions and arctic life forms that amplify the potential negative impacts of oil spills in arctic waters. In arctic conditions, oil lasts much longer, as it evaporates more slowly, or it can be trapped in the ice or under the ice, as a result, it becomes difficult for bacterial decomposition. The recovery of flora and fauna after the accident is slower, as many species have a relatively long lifespan and a slower generation cycle. Figure 4 shows the process of oil field elimination via burning. 


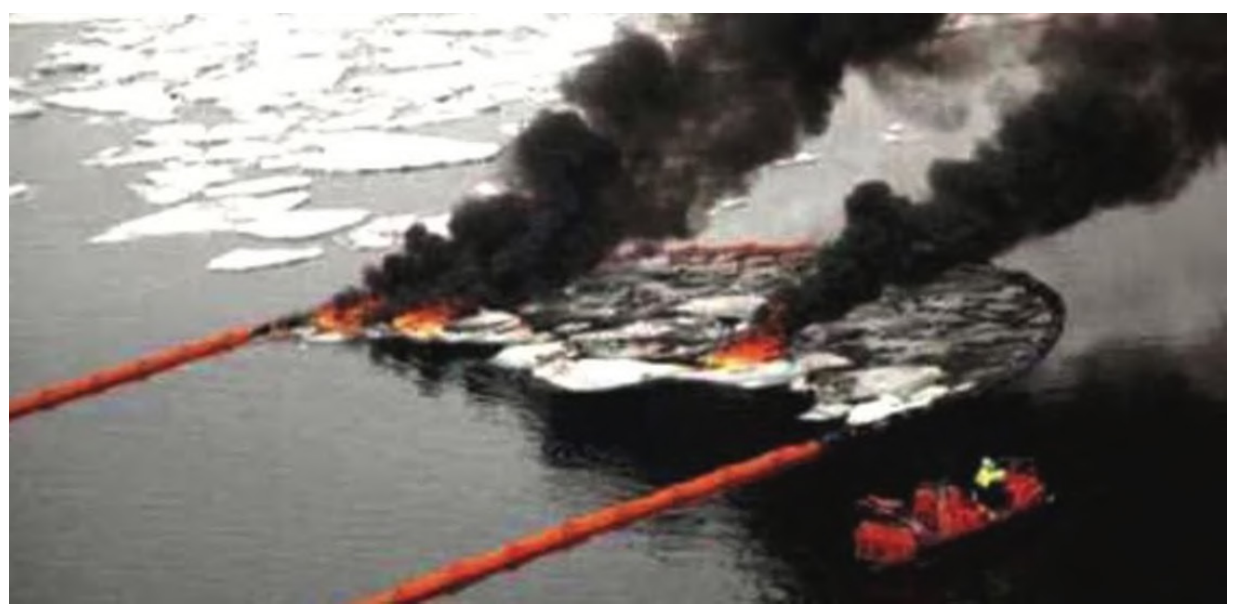

Fig. 4. Oil field burning.

\section{Conclusion}

The construction of oil and gas production facilities on land, shelf and in the ocean is associated with a huge range of risks to harm the environment. One of the most serious polluting factors is oil spills occurring at various stages of the construction and operation of a facility.

Now the engineering vanguard of mankind faces a very difficult and important task - to minimize harm to the environment. The solution of such a problem may require more than a dozen years, but it must be solved in one way or another and should also lead to the fact that in the foreseeable future the issue of oil pollution of the environment does not even arise.

\section{References}

1. H. Ahmad, T.A. Khan, H. Durur, G.M. Ismail, A. Yokus, Analytic approximate solutions of diffusion equations arising in oil pollution, Journal of Ocean Engineering and Science (2020)

2. J. Chen, Z. Di, J. Shi, Y. Shu, Z. Wan, L. Song, W. Zhang, Marine oil spill pollution causes and governance: A case study of Sanchi tanker collision and explosion, Journal of Cleaner Production 273, (2020)

3. M.S. Ozigis, J.D. Kaduk, C.H. Jarvis, P. da C. Bispo, H. Balzter, Detection of oil pollution impacts on vegetation using multifrequency $S A R$, multispectral images with fuzzy forest and random forest methods, Environmental Pollution 256, (2020)

4. S.A. Buzmakov, Y.V. Khotyanovskaya, Degradation and pollution of lands under the influence of oil resources exploitation, Applied Geochemistry 113, (2020)

5. Q. Chen, B. Bao, Y. Li, Y. Liu, B. Zhu, J. Mu, Z. Chen, Effects of marine oil pollution on microbial diversity in coastal waters and stimulating indigenous microorganism bioremediation with nutrients, Regional Studies in Marine Science 39, (2020) 